\title{
APOIO INSTITUCIONAL: A PERCEPÇÃO DOS APOIADORES EM UMA MATERNIDADE PÚBLICA DE ALAGOAS
}

\author{
INSTITUTIONAL SUPPORT:THE PERCEPTION OF THE SUPPORTERS \\ IN A PUBLIC MATERNITY HOSPITAL OF ALAGOAS, BRAZIL
}

\author{
APOYO INSTITUCIONAL: LA PERCEPCIÓN DE LOS PARTIDARIOS \\ DE UNA MATERNIDAD PÚBLICA DE ALAGOAS, BRASIL
}

\author{
Nélida Aleixo Cassella ${ }^{1}$ \\ Felipe Rangel de Souza Machado²
}

\begin{abstract}
Resumo Este artigo analisa a atuação dos apoiadores institucionais em uma maternidade pública do estado de Alagoas, durante a trajetória de implantação da Política Nacional de Humanização. O estudo enfoca o fomento e o desenvolvimento das práticas da Política na instituição, de acordo com a visão desses apoiadores. Enfatiza-se a implementação da diretriz valorização do trabalho e do trabalhador, e incluem-se, nessa trajetória, as dificuldades e as facilidades encontradas pelos apoiadores nas instâncias de gestão, bem como na execução dos processos de intervenção. Este estudo situa-se no campo da pesquisa social em saúde, com enfoque qualitativo. Para tal, foram analisados documentos institucionais e realizadas pesquisas em profundidade com atores-chave do processo investigado. A verificação dos dados teve por base metodológica a hermenêutica dialética. Foi construída uma matriz analítica com duas macrocategorias e seis categorias operatórias, a fim de sistematizar e apresentar os dados coletados. A observação dos dados permitiu compreender as principais estratégias, empregadas pelos apoiadores no cotidiano de seus trabalhos, que favorecem o avanço da Política Nacional de Humanização, além de apontar as desconexões e os nós críticos a serem problematizados.
\end{abstract}

Palavras-chave humanização da assistência; gestão em saúde; política nacional de humanização; apoio institucional.
Abstract The The objective of this article is to understand the performance of the supporters in a public maternity hospital in the state of Alagoas, Brazil, during the course of implanting the National Humanization Policy, moreover, this study analyzed how the promotion and development of National Humanization Policy practices have been happening in the institution. So, it emphasizes the implementation of the guideline value of labor and worker, including, in this path, the difficulties and facilities found by the supporters combined with the management bodies and also in the fulfillment of intervention processes. The present study is based on the social health research field with qualitative approach. It has been analyzed institutional documents and conducted in-depth research with key actors in this process. The data analysis in methodological basis was Hermeneutics Dialectic. It was built an analytical matrix with two macro categories and six operative categories to organize and present the data collected. The analysis of data allowed to understand the main strategies used by supporters in daily lives of their work, which leads to National Humanization Policy progress and point disconnections and critical nodes to be problematised.

Keywords humanization of assistance; health management; national humanization policy; institutional support. 


\section{Introdução}

A Política Nacional de Humanização (PNH) tem sido experimentada em diversas áreas devido ao seu potencial de articular ações, bem como fortalecer indivíduos e coletivos. Tal potencial relaciona-se com os princípios que balizam esta política e buscam: superar a tradicional fragmentação das ações em saúde por meio da transversalidade; afirmar a indissociabilidade vivida na prática entre atenção e gestão; e valorizar e criar canais de vocalização dos sujeitos que ao mesmo tempo permitam a afirmação de sua autonomia e da necessidade de corresponsabilização na condução das políticas e da atenção na saúde. Para tanto, a PNH propõe a inserção do apoio institucional a fim de atuar em uma função gerencial, "que busca a reformulação do modo tradicional de se fazer coordenação, planejamento, supervisão e avaliação em saúde" (Oliveira, 2012, p. 224).

A consecução de tais objetivos ocorreria mediante o desenvolvimento de seis diretrizes básicas a serem implantadas por meio de dispositivos ${ }^{3}$ desenvolvidos por uma metodologia própria, denominada Apoio Paideia ou Método da Roda: ${ }^{4}$ acolhimento, gestão participativa e cogestão, ambiência, clínica ampliada e compartilhada, valorização do trabalhador e defesa dos direitos dos usuários. Para humanizar práticas de gestão e de cuidado, a PNH propõe a 'tríplice inclusão', que significa a inclusão de pessoas, de coletivos e de movimentos sociais nos processos indissociáveis de atenção e de gestão. Esta medida de inclusão supõe que os atores reinventem seus processos de trabalho e atuem como disparadores de mudanças nos modos de gerir e de cuidar (Brasil, 2013).

A busca pela consolidação da política de humanização tem se intensificado por meio de algumas iniciativas, dentre as quais se pode destacar o suporte aos cursos de formação em Apoiador da PNH. O principal objetivo é fazer com que os profissionais de saúde extraiam de suas vivências e experiências elementos disparadores de estudo e de pesquisa, ao mesmo tempo em que possam intervir nas suas 'realidades', tomando por referência a PNH (Brasil, 2010).

Em uma análise acerca das tecnologias de fomento da $\mathrm{PNH}$, considera-se que a transformação de práticas e de gestão, tidas como indissociáveis, acontece, em parte, pela intervenção da função apoio. No entanto, essa afirmação transfere uma imensa responsabilidade ao apoiador, na medida em que o legitima como base da relação entre os sujeitos (gestores, trabalhadores e usuários).

Diante disso, sentimos a necessidade de problematizar o sentido e as contradições relacionados à função de apoiador institucional, a fim de melhor compreender as suas potencialidades, bem como as motivações que os levam a optar pela função. Este estudo tem como objetivo geral compreender 
o apoio institucional à luz da PNH, em uma maternidade pública de Alagoas, segundo a percepção dos apoiadores institucionais.

Já os objetivos específicos deste estudo são: analisar os efeitos produzidos pela PNH no cotidiano desses atores; identificar pontos divergentes entre aquilo que está previsto e o que tem sido realizado para a implementação da Política na instituição; e analisar a percepção dos apoiadores quanto ao fomento e ao desenvolvimento das práticas da $\mathrm{PNH}$, com ênfase na diretriz valorização do trabalho e do trabalhador.

A relevância deste estudo está relacionada tanto à necessidade de problematizar a realidade do SUS quanto à perspectiva de contribuir com as reflexões dos apoiadores em suas árduas tarefas de mobilizar sujeitos e coletivos, bem como de influenciar na construção de novos modos de gerir, de cuidar e de olhar para si mesmo e para o outro. Pretende-se, portanto, fornecer dados qualitativos que embasem e incentivem o fortalecimento do grupo de apoiadores, ao explicitarem-se os resultados favoráveis da pesquisa, e também as desconexões e os nós críticos a serem problematizados, a fim de que sejam construídas estratégias para consolidar a PNH na instituição e no estado de Alagoas.

\section{O espaço de atuação do apoio}

A humanização na saúde propõe um “conjunto de princípios e diretrizes que se traduzem em ações nas diversas práticas e esferas do sistema de saúde, caracterizando uma construção coletiva" (Brasil, 2004, p. 7). Para serem efetivas, as barreiras presentes nos diferentes níveis e instâncias que compõem o SUS precisam ser superadas por meio do diálogo e do fortalecimento entre os profissionais e entre os grupos. Assim, o conceito de transversalidade surge como um eixo que propõe mudanças em um modelo de comunicação tradicionalmente hierarquizado e verticalizado (Pasche, Passos e Hennington, 2011).

Essa medida de inclusão supõe que os atores reinventem seus processos de trabalho e atuem como disparadores de mudanças nos modos de gerir e de cuidar (Brasil, 2013). No entanto,

(...) é complicado atribuir aos "sujeitos sociais" a responsabilidade para a mudança no processo de produção de saúde. Essa análise não pode ser realizada descolada da realidade histórico-social em que estamos situados. Não é possível considerar "apenas" a "inclusão" de sujeitos, nesses processos, senão em como avançar no marco dos direitos já resguardados pelo SUS (Conceição, 2009, p. 205, grifos do autor). 
Esta autora destaca a estruturação da PNH como fortemente pautada em atestar ideias e conceitos distantes de serem concretizados. Isso fica evidente quando vivenciamos as formas precárias e fragmentadas de atendimento à população, consequência do escasso recurso destinado à saúde e da expropriação de direitos, principalmente os sociais, enquanto reflexo da contrarreforma neoliberal do Estado. Desse modo, se a Política não considera que essas e outras questões do contexto estão para além da inclusão de 'sujeitos sociais', pode contribuir, de forma incoerente, para velar as inúmeras contradições sociais e os problemas estruturais existentes no SUS.

O tema humanização, principalmente a PNH, é reafirmado em publicações por seu modo de operar e pelo apoio institucional, que é percebido, nesse estudo, como uma função exercida por trabalhadores que foram capacitados através de cursos ou oficinas sobre essa política. Entre os seus objetivos estão intervenções que buscam transformar práticas, tanto no âmbito da clínica quanto no da gestão, consideradas na $\mathrm{PNH}$ como intrínsecas e indissociáveis (Campos, 2000; Pasche, 2009).

Entretanto, percebe-se que existem algumas contradições que envolvem essa função. Destaca-se, inicialmente, que a visão de grande parte dos trabalhadores sobre a $\mathrm{PNH}$, por vezes, é guiada pela falta de conhecimento e de informação. Além disso, a visão que se tem acerca do papel do apoiador institucional nem sempre é clara para os trabalhadores e gestores ou nem mesmo para os próprios apoiadores. Isso ocorre, em parte, segundo o que pudemos captar nesta pesquisa, devido às constantes mudanças na nomenclatura adotada pelo Ministério da Saúde (MS). Na prática, percebe-se certa confusão entre os atores para entenderem qual o seu território de atuação e o tipo de apoiador que representa: se matricial, regional, integrado, centralizado, local, temático ou, mais recentemente, generalista. Essa configuração pode ser observada no Quadro 1.

\section{Quadro 1}

Histórico da Política Nacional de Humanização em relação ao apoio institucional - 2003 a 2016.

\begin{tabular}{|ll|}
\hline Período & Movimento histórico \\
\hline & - A Política Nacional de Humanização (PNH) foi a primeira área do Ministério da Saúde a \\
& utilizar os termos 'cogestão' e'apoio' em suas concepções; \\
& - Oficinas de humanização iniciaram o processo de capilarização da PNH; \\
& - Os termos 'cogestão' e'democratização institucional'aparecem na primeira versão do texto- \\
& base da PNH; \\
& - A função'apoio' foca duas dimensões: apoio matricial da PNH às demais áreas do Ministério \\
& da Saúde e apoio regional às secretarias estaduais e municipais de saúde, polos de educação \\
& permanente e serviços (Brasil, 2004); \\
& - Contratação de oito apoiadores/consultores regionais. \\
& - O apoio matricial: é definido no glossário do Documento-base (Brasil, 2004). \\
\hline
\end{tabular}




\section{Continuação - Quadro 1}

Histórico da Política Nacional de Humanização em relação ao apoio institucional - 2003 a 2016.

\begin{tabular}{|c|c|}
\hline 2006 & $\begin{array}{l}\text { Na terceira edição do Documento-base, a PNH esclarece a definição de apoio institucional } \\
\text { e o diferencia do apoio matricial. }\end{array}$ \\
\hline & $\begin{array}{l}\text { - Na quarta edição do Documento-base, de 2008, a PNH destaca o apoio como uma função } \\
\text { gerencial e amplia o seu conceito; }\end{array}$ \\
\hline 2008 & $\begin{array}{l}\text { - O Departamento de Apoio à Descentralização (DAD), mesmo sem empregar o conceito } \\
\text { apoio institucional, referenciou-se no 'apoio paideia' para definir o apoio integrado como } \\
\text { uma estratégia (Brasil, 2004). }\end{array}$ \\
\hline 2009 & $\begin{array}{l}\text { - A primeira edição do Documento-base de } 2009 \text { define o apoio matricial como a constituição } \\
\text { de rede de especialistas que apoiam o trabalho de equipes de atenção básica (Brasil, 2009, p. 28). }\end{array}$ \\
\hline & $\begin{array}{l}\text { - A Secretaria Executiva coordena o Núcleo Gestor do Apoio Integrado (NGAI), que é composto } \\
\text { por diversas secretarias do Ministério da Saúde; }\end{array}$ \\
\hline 2011 & $\begin{array}{l}\text { - Fortalecimento da cogestão e da contratualização de responsabilidades entre os entes, com } \\
\text { a participação de trabalhadores, gestores, usuários e prestadores de serviços; } \\
\text { - O Ministério da Saúde incentivou a implementação de redes temáticas, com foco central } \\
\text { na ampliação do acesso e da qualidade. }\end{array}$ \\
\hline & $\begin{array}{l}\text { - Em 2012, o documento "Diretrizes do apoio integrado para a qualificação da gestão e da } \\
\text { atenção no SUS" define os movimentos coletivos como espaço de atuação do apoiador } \\
\text { institucional, que articula cuidado e gestão, e busca novos modos de operar e produzir } \\
\text { saúde nas instituições; } \\
\text { - Esses atores deverão amparar estados e municípios no planejamento estadual, municipal } \\
\text { e regional, na definição e implementação das Redes de Atenção à Saúde (RAS), com ênfase } \\
\text { nas redes temáticas; }\end{array}$ \\
\hline 2012 & $\begin{array}{l}\text { - O Ministério da Saúde retoma a diferenciação feita em 2003-2004 pela PNH e pelo DAD, } \\
\text { entre apoio geral e apoio específico/matricial; } \\
\text { - Agora aparece como: apoiador e apoiador temático. Apesar de não considerar o apoiador } \\
\text { temático como matricial, a definição é semelhante à conceituação de apoio matricial construída } \\
\text { pela PNH; } \\
\text { - O apoio institucional, é inserido na produção do Departamento de Atenção Básica apenas em } \\
\text { 2011. Inicialmente, a Política Nacional de Atenção Básica (PNAB) considera o apoio institucional } \\
\text { como competência dos gestores dos três entes federados. }\end{array}$ \\
\hline 2013 & $\begin{array}{l}\text { - O “Guia para apoio institucional à implementação da Rede Cegonha do MS (2013)" nomeia } \\
\text { diversas modalidades de apoio:'apoio institucional temático','apoio institucional de maternidade' } \\
\text { e'apoio institucional regionalizado'. Que deverão atuar sinergicamente com base no princípio } \\
\text { da inseparabilidade entre atenção e gestão. }\end{array}$ \\
\hline 2015 & $\begin{array}{l}\text { - A atual gestão do Ministério da Saúde determina o encerramento das ações de apoio dos } \\
\text { consultores aos territórios e extingue o cargo; } \\
\text { - O grupo gestor do Ministério da Saúde aposta em estratégias para fortalecer as RAS, com } \\
\text { foco no fortalecimento da regionalização. Nasce o Apoio Generalista ou Descentralizado. }\end{array}$ \\
\hline 2016 & $\begin{array}{l}\text { - Apoiador Descentralizado + Apoiador Articulador: terá o papel de mobilizar os encontros } \\
\text { do coletivo de apoiadores no mínimo uma vez por mês, com vistas à troca de saberes e } \\
\text { informações; } \\
\text { - Regiões de saúde sentem necessidade de apoio para a implantação das políticas; } \\
\text { - Elaboração de um plano de ação que orientará a atuação do/s apoiador/es no âmbito da } \\
\text { região de saúde e possibilitará, ao Ministério da Saúde, o monitoramento. }\end{array}$ \\
\hline
\end{tabular}

Fonte: Os autores, com dados extraídos de Brasil (2008); Mori e Oliveira (2009); Pereira-Junior e Campos (2014). 
Nesse sentido, surgem alguns questionamentos, a exemplo de: como os gestores percebem os apoiadores institucionais que têm como funções produzir novos sujeitos, viabilizar pactos entre os atores e, principalmente, fomentar grupos para que sejam capazes de estabelecer novos referenciais na gestão do SUS? Embora seja clara a relevância da função apoio institucional (Oliveira, 2012; Campos, 2000; Pasche, 2009), existe espaço para que o apoiador conduza o princípio da indissociabilidade entre atenção e gestão por meio da cogestão?

Mori e Oliveira (2009, p. 637) afirmam que "construir coletivos de cogestão para dentro da $\mathrm{PNH}$ tem sido um desafio constante, processo por vezes difícil e desencadeador de tensionamentos". Percebe-se que os desenhos organizacionais pré-formatados no interior dos estabelecimentos, constituem um grande obstáculo para qualquer sujeito ou coletivo que se preocupe com a eficiência e eficácia na produção de saúde.

Nesse contexto, Vasconcelos e Morschel (2009) nos convidam a refletir sobre a formulação da $\mathrm{PNH}$, no sentido de compreender se os compromissos ético-políticos dos métodos, das estratégias e dos dispositivos por nós adotados têm contribuído de fato para a construção de referenciais compatíveis com o atendimento humanizado e também com a valorização da vida,

ou se o uso que tem sido feito de tais indicações tem servido para maquiar, sob novos rótulos e dispositivos, lógicas de cuidado privatistas, especialistas e universalistas, justamente aquelas que pretendemos, com tal política, ultrapassar (Vasconcelos e Morschel, 2009, p. 731).

\section{O caminho percorrido}

A proposta apresentada neste estudo teve uma abordagem qualitativa. Nosso olhar se voltou para a análise da construção coletiva de determinada estratégia de atuação política e buscou captar as percepções individuais, no intuito de compor um quadro mais nítido a respeito da PNH na instituição. A pesquisa foi realizada na Maternidade Escola Santa Mônica (MESM), que atendeu a alguns critérios como: a PNH estava em fase de implementação; e a instituição era acessível a pesquisadores e existiam apoiadores institucionais em seu quadro permanente.

A MESM é um dos núcleos que compõem a Universidade Estadual de Ciências da Saúde de Alagoas (Uncisal) e faz parte de um contexto que busca a humanização de práticas que resultem em um melhor atendimento obstétrico e neonatal. No entanto, de acordo com Ferreira (2015), o processo de implementação de ações e de dispositivos norteados pelos princípios e pelas diretrizes da PNH na maternidade tem ocorrido em 
condições político-institucionais desfavoráveis reveladas em indicadores, tais como: a) inadequação da estrutura física e ambiência; b) carência de profissionais para cobertura da escala de trabalho; e c) situações de constante superlotação no atendimento na porta de entrada (Ferreira, 2015, p. 12)

Os profissionais que participaram da pesquisa foram incluídos no estudo mediante os seguintes critérios contextuais: ser apoiador institucional capacitado por meio de Curso de Formação de Apoiadores da PNH, ou de Oficinas de Humanização; estar lotado na instituição e aceitar participar da pesquisa. Optamos para este estudo por análise documental e entrevista semiestruturada, além de pesquisa bibliográfica.

Para a análise documental, escolhemos documentos internos e optamos por não priorizar ou especificar o tipo documental a ser analisado. Reunimos tudo que estivesse relacionado à estruturação da MESM e pudesse ser consultado durante a investigação.

Foram realizadas sete entrevistas com os sujeitos que compõem hoje o coletivo de apoiadores na MESM, durante todo o mês de março de 2016, após o Comitê de Ética em Pesquisa da Escola Politécnica de Saúde Joaquim Venâncio, Fundação Oswaldo Cruz, conceder o parecer favorável ao projeto.

As entrevistas foram semiestruturadas, e para sua realização foi elaborado um instrumento com questões abertas. Esse roteiro foi norteado por alguns elementos, quais sejam: experiências vivenciadas pelo apoiador quanto ao incentivo por parte da gestão no processo de implementação da Política; fomento de dispositivos, mecanismos e rodas de discussão para construção de novos processos de trabalho; processos de formação e educação permanente que visam à competência técnica e humana dos trabalhadores e gestores; pontos divergentes entre o proposto pela Política na instituição e o previsto na PNH; motivação pessoal e profissional para atuar na função apoio; fomento e desenvolvimento das práticas da $\mathrm{PNH}$, com ênfase na diretriz valorização do trabalho e do trabalhador.

As entrevistas foram gravadas e transcritas literalmente. Na transcrição, os apoiadores foram identificados pela letra 'A', seguida de um número que não corresponde à ordem das entrevistas. Manteve-se, por questões éticas, o anonimato dos participantes e do seu setor de trabalho.

Adotamos como técnica de análise do material coletado a hermenêutica dialética. Conforme Minayo (2014, p. 328), “a hermenêutica fundamenta-se na compreensão" e a dialética aplica como instrumento de interpretação o conhecimento histórico, já que o entendimento da linguagem e da comunicação expressa a experiência, a prática e a vivência dos indivíduos.

Para a análise de dados, empregamos, conforme orientação desta autora, os seguintes passos metodológicos: ordenação, classificação e análise final. 
Considera-se que essas fases não são estáticas e, portanto, comunicam-se e se complementam.

\section{Ordenação e classificação dos dados}

A ordenação dos dados partiu, inicialmente, dos seis eixos norteadores, os mesmos do questionário usado na entrevista. Foram construídos quadros para a consolidação das entrevistas, para a comparação dos dados e para a organização dos comentários/respostas. Na segunda etapa, tomamos como guia um modelo de matriz analítica que facilitou delinear no material a presença de dois eixos principais de análise, subdivididos em categorias operatórias interligadas e que se comunicam, em um movimento de idas e vindas.

Figura 1

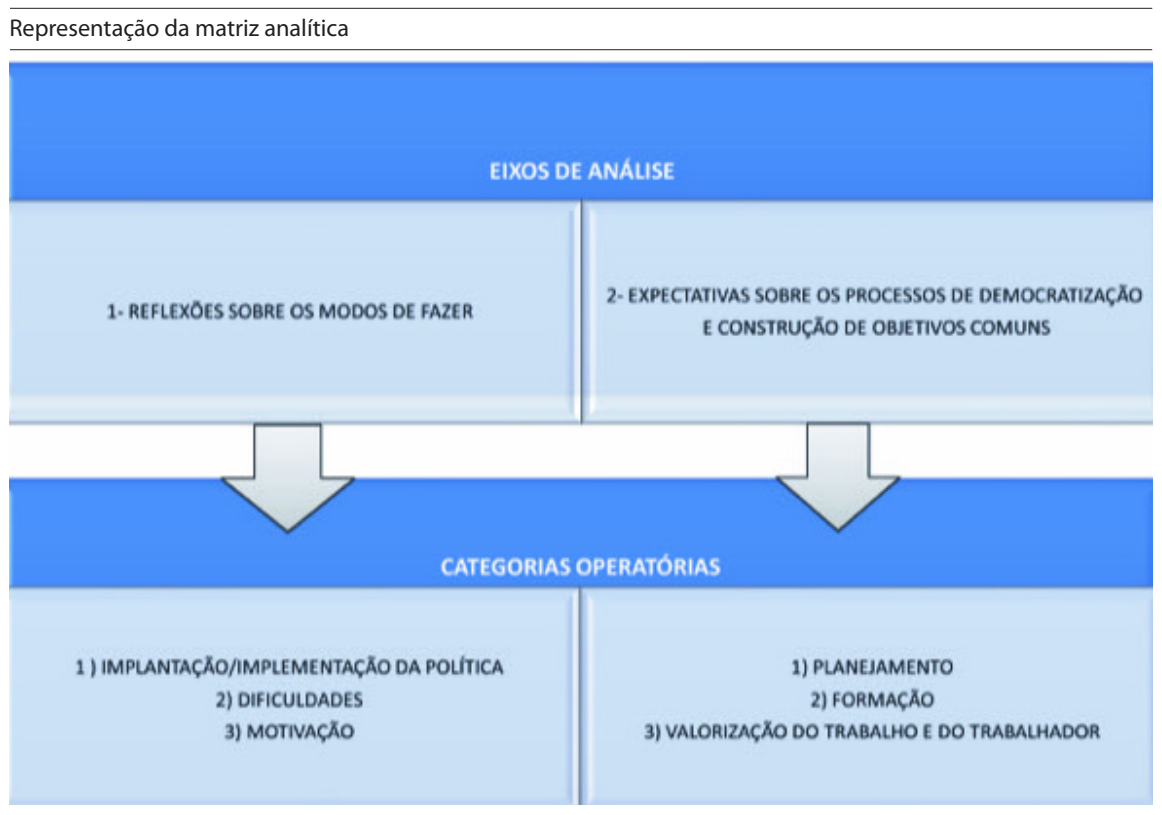

Fonte: Elaborado pelos autores com base no modelo de Pinheiro et al. (2013).

No processo final de análise, procurou-se resgatar os eixos norteadores das questões iniciais e os objetivos propostos. Fundamentou-se a pesquisa com base em recortes que apontaram para o pensamento dos apoiadores quanto aos eixos selecionados e identificaram-se as diferenças e semelhanças de pensamento sobre o apoio institucional entre os entrevistados. 


\section{Reflexões sobre os modos de fazer}

Essa categoria operatória procurou reunir a percepção dos apoiadores sobre a trajetória de implantação/implementação da Política na maternidade, ou seja, a sua participação e o seu envolvimento nesse processo. Dentre as medidas consideradas pelos apoiadores está a cogestão, cuja proposta é a reformulação da racionalidade gerencial hegemônica e o incentivo à produção de diferentes modos de se conduzir os coletivos nas organizações (Campos, 2000). Essa proposta daria aos trabalhadores a oportunidade para que cada um tomasse as suas próprias decisões, dentro do espaço de poder que lhe é conferido.

Para a cogestão acontecer não basta estar inserida na estrutura organizacional da instituição, ou seja, não é suficiente a imposição do corpo gerencial. Muitas vezes, um grupo colegiado nada mais é do que uma concentração de individualidades que nada têm em comum. A PNH propõe, nesse sentido, “a constituição de espaços onde a efetiva prática do debate se concretize" (Silva, Barros e Martins, 2015, p. 1.160).

Os relatos demonstraram que a realidade gerencial vivenciada em todo o percurso de implantação distancia-se do ideal democrático e permanece, ainda hoje, pautada em movimentos controladores e pouco flexíveis, o que enfraquece a autonomia e o protagonismo dos trabalhadores em questão, ou seja, os apoiadores. Os relatos de alguns apoiadores revelam preocupações quanto à formatação dos Colegiados de Gestão ${ }^{5}$ na instituição. Esse problema foi apontado como um dos dificultadores no processo de implementação da cogestão.

A gente não foi formado para gestão colegiada, aí se pega um monte de gente sem formação, bota numa sala, bota numa roda e diz [:] a partir de hoje a gestão é colegiada. Claro que não vai acontecer (...) Tem que haver processo de formação desses conselheiros, desses gestores, mas é uma quebra de paradigma muito grande em que se um elo quebra, complica. Não adianta se ter um comitê ou conselho gestor e as coordenações não estarem na mesma lógica, porque de um lado vai ter uma discussão horizontalizada e do outro o processo de trabalho será verticalizado. Esse para mim é o grande desafio (A5).

(...) os participantes do colegiado têm que ter uma formação, porque na verdade, eles não sabem nem qual é o papel do colegiado (...) O que existia antes, e o que existe até hoje, é a reunião de coordenadores, que na verdade é um tipo de colegiado de gestão... só que não é representativo, porque os coordenadores têm indicação da direção (Al). 
Na percepção dos apoiadores, a cogestão é uma realidade um pouco distante, já que ainda é instituída uma gestão vertical ou 'cartorial', baseada na lógica da gestão do 'cumpra-se'. Nas palavras dos entrevistados:

As comunicações aqui são enviadas por papel, então chega para nós aquela comunicação e cumpra-se (...) Então, eu acho que o maior entrave e o maior desafio é romper mesmo essa forma de funcionar, com a gestão aqui em cima. E a indissociabilidade entre a atenção e a gestão? (A4).

As reflexões sobre a instabilidade dos apoiadores emergem do distanciamento da gestão em relação à figura do apoiador como parte integrante do processo de implementação da Política. Esse ainda não é identificado como um ator que poderá favorecer a comunicação entre os grupos, ao articular e planejar ações e intervenções que reverberem em práticas humanizadas tanto no serviço quanto na gestão. Em um modelo de gestão democrática, “diferentemente das tradicionais assessorias e consultorias, o apoiador não faz pela ou para as equipes, e sim com as equipes, apoiando a análise, elaboração e planejamento de tarefas e projetos de intervenção" (Pereira-Junior e Campos, 2014, p. 896).

Percebe-se que o desejo dos apoiadores não está em buscar e encontrar soluções mágicas para implementar os princípios e as diretrizes de uma política que vise à transformação de práticas para uma assistência mais humana à população. Apesar das dificuldades, o que se deseja evidenciar é que existem sujeitos/trabalhadores comuns, comprometidos, que optaram por se engajar em uma luta para a construção e consolidação de um SUS melhor. Assim, "mais que seguidores, a PNH incentiva e alimenta-se de sujeitos que tomam como desafio superar os obstáculos enfrentados no processo de construção do SUS" (Martins, 2015, p. 67).

\section{Dificuldades}

No que diz respeito às dificuldades, a escassez de recursos aparece como um dos principais problemas no cotidiano do apoiador, conforme expressado na seguinte fala: "É a falta de recursos estruturais, de recursos financeiros e falta de condições de trabalho, de materiais, de insumos, de ambiência" (A2).

Outro ponto elencado como dificultador se refere ao entendimento que as pessoas têm de que humanização "é só dar boa tarde, é ser receptivo, é cordialidade, é comemoração" (A7). Nesse contexto, há certa urgência em repensar as concepções e convenções arraigadas na compreensão sobre humanizar. Benevides e Passos (2005, p. 562) já alertavam quanto a essa necessi- 
dade, ao identificar a equiparação da humanização “a movimentos religiosos, filantrópicos ou paternalistas".

Os trabalhadores não conseguem visualizar a figura do apoiador como um agente de fomento e de disseminação de práticas com o olhar da humanização. Não compreendem que eles necessitam do coletivo e que sua atuação é apoiada pela compreensão e pelo reconhecimento da autonomia e do protagonismo do sujeito.

É essa concepção cristalizada e fragmentada que reduz a humanização a “iniciativas pontuais correndo o risco de substituir a totalidade da realidade por noções elementares dos fatos, frequentemente supervalorizados com motivação demagógica" (Puccini e Cecílio, 2004, p. 1.346).

Algumas adversidades relacionadas aos cursos foram citadas e se referem à forma de condução, à necessidade do acompanhamento das ações em campo e a falta de clareza quanto ao espaço de atuação do apoiador.

Eu acho que houve um foco muito grande nos problemas que existem nas unidades assistenciais. Mas não deu muito amparo de como fazer, não nos deu uma diretriz de como e quais os caminhos a serem seguidos, do como chegar... Nesse ponto, deixou um pouco a desejar (A5).

A grande questão hoje é como esse trabalhador que é psicólogo, que é assistente social, que é médico, qualquer que seja a sua categoria. Como ele vai atuar como apoiador dentro da unidade que ele trabalha? (...) Eu acho que esse ainda é o grande ponto de discussão para os cursos de formação (A4).

Em seu discurso, os apoiadores buscam o exercício da democracia. Eles acreditam e defendem princípios metodológicos, como o Método da Roda, "que apoia, de modo simultâneo, a elaboração e implementação de projetos e a construção de sujeitos e coletivos organizados" (Campos, 2000, p. 185), e pode, assim, conduzir o apoiador para uma melhor forma de lidar com as diversas situações no cotidiano do trabalho. Porém, para que isso aconteça, é necessário que sejam primeiramente definidas e entendidas as diferenças, já que fazer com que os gestores conheçam e aceitem outras lógicas é possivelmente um dos maiores desafios da PNH.

\section{Motivação}

As narrativas dos apoiadores nos levam a crer que a sua mobilização e o seu compromisso são diretamente proporcionais à sua indignação, ao seu inconformismo e ao espírito de luta de cada um. Eles acreditam que mudan- 
ças podem acontecer mediante transformações individuais e coletivas, por intermédio dos seus ideais de trabalho, de relações e de valores. O desejo aqui "refere-se ao inconsciente, e a sua manifestação ocorre independente da existência de meios necessários a sua realização" (Campos, 2000, p. 75). Um apoiador se coloca a esse respeito na fala a seguir:

A motivação que eu tenho é proporcional à necessidade que eu vejo dos trabalhadores serem mais valorizados, mais apoiados (...) Tive a oportunidade de ouvir muitas queixas, muitos sofrimentos, e eu acho que nós podemos ajudar e podemos apoiar de alguma forma. A gente se sente impotente diante das condições, das situações. Mas, temos esperança, e assim, vamos driblando o sentimento de impotência (A2).

Compreendemos que essa mobilização "persegue uma articulação que propicie a participação ativa de todos os atores e instâncias que compõem o sistema" (Santos-Filho, 2007, p. 75), na esperança de superação das fragmentações e dicotomias tão evidentes nos processos de trabalho.

Hoje a minha principal motivação é porque ainda acredito na micropolítica, transformando os processos e mudando a rotina, mudando o modo como enxergamos e nos posicionamos na realidade. Acredito na capacidade que temos de influenciar os processos e influenciar as pessoas (A5).

Eu me motivo por acreditar que as coisas podem melhorar, contribuir para mudanças de pensamento, de atitude, de tratamento como melhoria na qualidade da assistência, tanto do usuário quanto do servidor (A7).

Pensamento contrário também esteve presente em alguns relatos, como o seguinte: "Perdemos a motivação de ir às rodas, porque a essência da Política é só proforma" (A7). A principal crítica é de que a Política possui muito discurso e pouca eficácia, e questiona, afinal, "o que ela muda concretamente?" (A7).

\section{Expectativas quanto aos processos de democratização para construção de objetivos comuns}

A categoria operatória 'planejamento' surge como uma alternativa para a construção de objetivos comuns, pois, nas narrativas, as expectativas dos apoiadores versam sobre as adversidades vivenciadas no caminho do construir junto. 
Esse caminho tem sido considerado árduo, já que na MESM “o modus operandi não está condizente com a Política" (A4). Esse percurso, apesar de estar teoricamente bem estruturado, na percepção dos entrevistados, ainda não valoriza as relações de horizontalidade e se distancia do previsto na $\mathrm{PNH}$.

Os relatos expressaram que, para ser efetivo, todo e qualquer caminho que leve a um planejamento deveria ser realizado em conjunto, para que os trabalhadores pudessem expor suas ideias com base nas suas necessidades. Consta no Planejamento Estratégico (PE) da Uncisal 2014-2024: “estruturar uma gestão de pessoas voltada ao desenvolvimento institucional, através do fomento e execução de ações com foco nos servidores e na humanização". No entanto, os caminhos percorridos até agora apontam para uma evidente necessidade de reestruturação da função apoio, com a finalidade de impulsionar essas e outras mudanças.

As reflexões denotam uma fragilidade do apoio, devido à ausência de escuta. Há uma preocupação quanto ao livre acesso nas pontes que conduzem para as 'gerências de portas abertas' e fica claro que, apesar de acessíveis, existe uma grande diferença entre o ouvir e o escutar, pois "ser ouvido representa, nesse processo, algo que ultrapassa a possibilidade auditiva de cada um" (Backes, Lunardi-Filho e Lunardi, 2006, p. 226).

(...) Entre ouvir e escutar existe uma grande diferença, muitas vezes eu sentia que era ouvida, mas não era escutada, entendeu? (...) Porque tinha outros problemas maiores, muito maiores do que aqueles que eu estava levando, ou as propostas que eu estava fazendo não tinham tanta importância (A2).

São caminhos que quase sempre conduzem a um sentido oposto e identificam, assim, o quão distante os apoiadores estão de atuar com a autonomia e o protagonismo prescritos pela $\mathrm{PNH}$.

Essa categoria está muito interligada às dificuldades enfrentadas nas práticas de planejamento e dizem respeito à limitada implementação do viés participativo. Para Santos-Filho (2007, p. 89), as equipes deveriam ser moldadas como "equipes colegiadas, planejando, avaliando e tomando decisões coletivamente".

\section{Formação}

Não foi proposta deste estudo realizar uma análise acerca dos processos formativos, entretanto, nesta categoria, consideramos relevantes algumas considerações tecidas por autores, bem como colocações de alguns apoiadores quanto ao fato de o processo formativo contribuir para a sua atuação. Ceccim (2005, p. 165) considera que “a Educação Permanente em Saúde pode ser 
orientadora das iniciativas de desenvolvimento dos profissionais e das estratégias de transformação das práticas de saúde". Afirma ainda que, desde o momento que se problematizam as adversidades no cotidiano do trabalho, as transformações desejadas ocorrem naturalmente e são firmadas em bases concretas. Segundo Al, “apesar da importância da formação, é na experiência que o apoiador se constitui, mas, para que isso efetivamente ocorra, é necessária a validação da gestão".

Por outro lado, Campos, Cunha e Figueiredo (2013) questionam até que ponto o ensino 'problematizador' é suficientemente forte para preparar e empoderar os sujeitos na difícil tarefa de enfrentar e promover mudanças na realidade dos serviços, uma vez que as práticas relacionadas à gestão verticalizada, à fragmentação das equipes, às relações interpessoais conflitantes e à precariedade na atenção, entre outros problemas, foram fortemente estabilizadas e enraizadas ao longo do tempo. Nesse contexto, os autores acreditam que "a proposta de Educação Permanente acaba por subestimar a força dos saberes, instituições e práticas hegemônicas, consolidadas historicamente ." (Campos, Cunha e Figueiredo, 2013, p. 142).

Em linhas gerais, a maioria dos apoiadores considerou como positivo especificamente o processo de formação em PNH no momento da sua implantação na instituição, por favorecer a criação de um coletivo de apoiadores que atuariam, posteriormente, como multiplicadores em outros cursos, bem como na implantação de projetos de intervenção.

No primeiro momento, a gente apostava muito na questão dos cursos formais. Mas no final, o impacto disso na realidade do serviço era muito pequeno (...) hoje, eu aposto mais nos processos formativos menores, dentro do serviço. Educação Permanente com o coletivo de humanização exercendo o papel formativo em pequenas oficinas vinculadas aos projetos (A5).

Os apoiadores apontam para uma necessidade de multiplicação dos conhecimentos, como caminho metodológico para transformações nas diversas dimensões do desenvolvimento humano, ou seja,

ao se discutir a ação, as mudanças começam a acontecer naturalmente (A3).

Para alguns apoiadores, existe a compreensão de que ao transformar a si mesmo as mudanças acontecem por contágio,

(...) Para mim, eu soube pegar todo aquele conteúdo teórico e transformar isso em ação e em mudança no meu setor de trabalho (A6). 
Eles também defendem a necessidade de realização de cursos e seminários para o fortalecimento do grupo.

Para fortalecer essa política, o servidor precisa ter o conhecimento. Sinto a necessidade de ver como as pessoas estão se comportando a partir do conhecimento. É necessário fazer entender que tudo faz parte de uma cadeia e a PNH, é um elo de ligação (A3).

Eu acho que os cursos trazem uma grande contribuição, mas é importante que continuem para que outras pessoas possam ser preparadas e deem continuidade ao processo. Entendo que as mudanças só surgem a partir do conhecimento, se não se educa, não se conseguem mudanças (A7).

Ceccim (2005) acredita que podemos apostar em diferentes práticas educativas como alternativas

para desfazer as dicotomias persistentes e sobre as quais foram construídas as iniciativas anteriores de mudança (individual X coletivo, clínica X saúde pública, especialidade $\mathrm{X}$ generalidade, sofisticação tecnológica X abordagens simplificadas) (Ceccim, 2005, p. 165).

Tradicionalmente, imputa-se ao processo formativo a responsabilidade pelas mudanças que possam vir a ocorrer na qualidade dos serviços, sem considerar que os atores possuem singularidades e "a vivência e/ou a reflexão sobre as práticas vividas é que podem produzir o contato com o desconforto e, depois, a disposição para produzir alternativas de práticas e de conceitos" (Ceccim, 2005, p. 165).

\section{Valorização do trabalho e do trabalhador}

A saúde do trabalhador aparece como uma das diretrizes da PNH para disparar mudanças nos espaços de produção de saúde. Mas, quais valores são afirmados e priorizados como investimento na saúde desse trabalhador?

Os apoiadores abordaram diferentes ângulos acerca da valorização do trabalho e do trabalhador (VTT) como prioridade na instituição. A maioria dos relatos evidenciou um desgaste quanto às diversas conotações e nuances que permeiam o termo 'valorização' no cenário estudado. Desse modo, as falas indicam que é necessário ir além do que se tem implantado em termos de VTT na instituição, bem como que há um atraso em relação à implementação da PNH (A2, A3, A6). Nos relatos, os apoiadores se reportaram a algumas 
questões já discutidas anteriormente, tais como: gestão verticalizada, não participação em espaços decisórios e comemorações festivas com encontros pontuais. Identifica-se que boa parte das frustrações dos apoiadores é reflexo das rígidas, inflexíveis e centralizadoras relações de trabalho.

Uma entrevista trouxe à tona impasses relacionados ao “(...) sofrimento e ao abandono dos servidores, eles se sentem cuidadores descuidados" (A5). Desse modo, deve-se estar atento para que os processos e ações que visem melhorar as condições de trabalho por meio de controle de fatores de risco, adequação de estrutura física e promoção de saúde, dentre outros, não sejam reduzidos ao acompanhamento de indicadores tradicionalmente usados no campo biomédico. Ressalta-se ainda a importância do olhar crítico sobre o cardápio organizacional com ofertas que incluam em sua agenda "lazer, técnicas diversas de relaxamento, socialização e práticas similares, quase sempre isoladas da discussão de sua inserção no trabalho" (Santos-Filho, 2007, p. 148).

Estiveram presentes ainda em algumas falas: a questão salarial; o plano de cargos, carreira e remuneração; a aquisição de equipamentos e insumos; e a ambiência inadequada. A desvalorização foi ressaltada no que se refere à falta de critérios no momento de se instituir gratificações. É também comum que, em um mesmo setor, alguns trabalhadores recebam adicionais e outros não. Para o apoiador é desgastante conviver com tamanha desigualdade, conforme pode ser percebido:

Existe muito a valorização de uns e de outros não. Não vejo a valorização apenas pelo dinheiro, acho que a valorização do trabalho e do trabalhador é ter o reconhecimento de que você representa algo para a instituição. Infelizmente o que vemos, na prática, é aquele que menos contribui ser o mais valorizado. Se as pessoas fossem valorizadas pelo seu potencial, só acrescentaria à gestão, a bola de neve cresceria para o lado bom e agregaria pessoas com diferentes valores e potenciais (A6).

Os relatos apontam na direção da valorização profissional como condição fundamental para disparar movimentos de transformação em qualquer processo de trabalho.

Faz-se necessário destacar que existe uma desarmonia entre os protocolos engessados e a prática cotidiana, a qual foge do convencionalmente prescrito, já que o inesperado é constante em situações que envolvem tecnologias e relações humanas.

Essa afirmação pressupõe que, por mais que a realidade organizacional do serviço imponha uma rotina com padronização de condutas e protocolos rígidos (compreendemos que são muitas vezes essenciais para um bom e resolutivo atendimento), não se consegue mudar a essência da vida e o modo humano de operar desse trabalhador. 
Eu sempre faço um ótimo acolhimento e, na verdade, eu já fazia antes de conhecer a Política. Eu me identifico com a PNH, mas, mesmo que ela não existisse, o meu ser já trata disso tudo. De valorização ao outro, de acolher. Eu faço isso porque é uma atuação que eu acredito (A4).

O meu interesse é que a pessoa que está do outro lado saia satisfeita, isso é o mais importante para mim. Se o outro não está satisfeito, eu também não estarei. Talvez eu já traga isso antes mesmo da política. Hoje, eu tenho 30 anos de serviço público, vejo esse comportamento como uma questão minha (A3).

Essa categoria nos levou a refletir sobre a quebra de paradigmas no sentido de valorizar o trabalho. Constatamos que esse percurso é bastante preocupante e inquietante, já que procura transformar visões intrínsecas a processos que envolvem diversos entraves, tais como: hierarquia entre as profissões; falta de análise das etapas dos projetos; relações interpessoais e de trabalho fragilizadas; fragmentação de setores; cultura da produtividade sem considerar a qualidade do serviço prestado.

Diante desse quadro, os apoiadores almejam um novo modo de pensar, uma evolução na liberdade, na autonomia e no protagonismo, para que possam contribuir com o combate à alienação e às pressões das organizações, entre outros. Os trabalhadores da saúde ainda têm que enfrentar desafios diários, visando, assim, não só à valorização da categoria, mas, também, a atingir o ideal do respeito humano, ou seja, uma verdadeira afirmação de outro modo de existir num sistema de saúde mais digno e democrático.

\section{Considerações finais: o desafio de ser apoiador}

Nas colocações dos apoiadores, as desejadas mudanças propostas pelos princípios e diretrizes da PNH seguem caminhos diversos e nem sempre alcançam os resultados esperados. Desse modo, percebe-se que ainda existe um descompasso entre o que é prescrito e o que é proposto como inovação da Política na maternidade, já que a análise dos documentos não aponta para uma influência do Método da Roda ou para a inclusão do apoio institucional na estrutura organizacional da maternidade. A maior parte dos documentos internos não cita e nem inclui os conceitos de cogestão e de apoio institucional.

Os pontos divergentes na percepção dos entrevistados apontam, inicialmente, para a falta de planejamento de processos emancipatórios, autônomos e protagonistas, os quais ganhariam espaço apenas por meio da legitimação da função apoio perante a gestão. Algumas limitações dos apoiadores estão relacionadas ainda à visão que os trabalhadores têm acerca da $\mathrm{PNH}$, o que esboça certa tendência à acomodação e à submissão, e se afasta de qualquer movimentação contestatória. 
Em geral, os trabalhadores ainda não compreendem a 'Roda' como fundamental, já que em sua lógica nada se constrói para as pessoas, mas sim com elas. Dessa forma, as análises indicam que a percepção do apoiador sobre o seu trabalho deveria girar em torno de criar oportunidades e envolver as pessoas em um caminho diferente e de construção coletiva, no qual reconheçam e se reconheçam no processo do humanizar.

Ao analisar a relação entre o apoiador e a gestão, nota-se que os apoiadores não veem a cogestão inserida no seu processo de trabalho, já que não existe a sua participação nos espaços de planejamento e de decisão. Isso torna evidente que a gestão da maternidade é pautada em uma configuração vertical ou decrescente e que, apesar do esforço constante, ainda não é permitido ao apoiador pensar o apoio como método de gestão democrática, o que limita, portanto, o caminhar transversal da $\mathrm{PNH}$ nos diversos setores que compõem a maternidade.

Outro ponto destacado relaciona-se à necessidade de implementação de um colegiado gestor devidamente preparado para exercer essa função. Isso, na percepção dos apoiadores, seria um sinal de democracia. Assim, fica claro que a cogestão de coletivos organizados

depende de vontade política e de condições objetivas, e o método da Roda se propõe a construí-las com a máxima racionalidade possível. Trabalhar os sujeitos e as instituições. Um movimento interferindo e modificando o outro. O tempo todo (Campos, 2000, p. 44).

Existe uma cultura instituída que não identifica as ações da PNH quando essa não tem uma conotação festiva. No entanto, os apoiadores entendem que precisam vencer a herança dessa cultura ao nomear e divulgar as práticas realizadas e fazer um elo com a humanização. Ficou evidenciada a dificuldade em desvincular a humanização da realização de eventos.

As dificuldades dos apoiadores os acompanham desde a formação, visto que se sentem isolados quando não conseguem lidar com as fragilidades do coletivo no cotidiano dos serviços. Por outro lado, o olhar expresso pelos apoiadores neste trabalho, reafirma as palavras de Oliveira (2011, p. 160), quando diz que "formar um apoiador é um ato próprio da função apoio. Não no sentido de que só alguém com um 'título' de apoiador institucional pode fazê-lo (...) É a relação de apoio que forma o apoiador".

Por intermédio dos depoimentos, pudemos perceber que os apoiadores não se sentem valorizados por não serem parte integrante dos espaços decisórios, o que reafirma um modelo de gestão distante de uma orientação horizontal, e não se configura um espaço para a coparticipação e a tríplice inclusão. 
Concluímos que, embora detentores de um grande potencial de intervenção, os apoiadores ainda não conseguem fomentar e consolidar na maternidade novos olhares acerca da humanização como proposta diferenciada de promoção de saúde e de vida. No entanto, há uma motivação e um desejo comum de que a humanização possa implicar, principalmente, um reconhecimento da valorização humana nas relações que caminhe para a concretização da igualdade material e não apenas formal.

Espera-se que, mesmo em um panorama permeado por dúvidas e indefinições, como política de governo, ocorram avanços no coletivo de apoiadores da MESM. Para isso, é necessário que o planejamento se aproxime cada vez mais das necessidades dos trabalhadores e usuários e favoreça, assim, um movimento constante. Isso passa pelo habitual, imprevisto, ocasional, o que humaniza e transforma o ambiente de trabalho também em uma coletividade de busca, de indagação, de observação, de pesquisa e de estudo, sempre girando... em roda!

\section{Colaboradores}

Nélida Aleixo Cassella conduziu a pesquisa de campo e atuou em todas as etapas de elaboração do artigo com base em sua dissertação de mestrado. Felipe Rangel de Souza Machado orientou a dissertação de mestrado e auxiliou na redação e na revisão crítica do artigo. Não existe conflito de interesses.

Resumen El objetivo de ese artículo es explayarse la acción de los partidarios en una maternidad publica del estado de Alagoas, Brasil, durante la ruta de distribución de la Política Nacional de Humanización. El estudio examinó como ocurre la promoción y el desarrollo de las prácticas de la Política en la institución, en la visión de esos partidarios. Enfatizase la implementación de la directriz valoración del trabajo y del trabajador, incluyendo, en ese camino, las dificultades y facilidades encontradas por los partidarios junto a las instancias de gestión y también en la ejecución 
de los procesos de intervención. Ese estudio situase en el campo de la pesquisa social en salud, con enfoque cualitativo. Fueran analizados documentos institucionales y realizadas pesquisas en profundidad con actores llave del proceso estudiado. El análisis de los dados tuve por base metodológica la Hermenéutica Dialéctica. Fue construida una matriz analítica con dos macrocategorías y seis categorías operacionales, con el fin de sistematizar y presentar los dados colectados. El análisis de los dados permitió comprender las estrategias utilizadas por los partidarios en el cotidiano de sus trabajos que favorecen el avanzo de la Política Nacional de Humanización, además de apuntar las desconexiones y los nudos críticos a problematizarse.

Palabras clave humanización de asistencia; gestión en salud, política nacional de humanización; apoyo institucional.

\section{Notas}

${ }^{1}$ Escola Técnica de Saúde Professora Valéria Hora, Maceió, Alagoas, Brasil.

$<$ nelida_aleixo@hotmail.com>

Correspondência: Rua Publicitário Ranildo Cavalcante, 118/402, Gruta de Lourdes, CEP 57052-782, Maceió, Alagoas, Brasil.

${ }^{2}$ Fundação Oswaldo Cruz, Escola Nacional de Saúde Pública Sergio Arouca, Rio de Janeiro, RJ, Brasil.

$<$ felipemachado@fiocruz.br>

${ }^{3}$ Por dispositivos entende-se a atualização das diretrizes de uma política em arranjos de processos de trabalho. Novos instrumentos que se aplicam para operar novos modos de produzir saúde, incluindo os coletivos nos processos de transformação dos modelos de atenção e de gestão (Brasil, 2008).

${ }^{4}$ Método crítico à Racionalidade Gerencial Hegemônica, propondo uma reconstrução operacional dos modos de fazer-se a cogestão de instituições e para a constituição de sujeitos com capacidade de análise e de intervenção (Campos, 2000, p. 234 ).

${ }^{5}$ Modelo de gestão participativa, centrado no trabalho em equipe e na construção coletiva (planeja quem executa), os colegiados gestores garantem o compartilhamento do poder, a coanálise, a codecisão e a coavaliação (Brasil, 2010, p. 56) 


\section{Referências}

BENEVIDES, Regina; PASSOS, Eduardo. Humanização na saúde: um novo modismo? Interface: Comunicação, Saúde, Educação, Botucatu, v. 9, n. 17, p. 389-406, 2005.

BRASIL. Ministério da Saúde. HumanizaSUS: a humanização como eixo norteador das práticas de atenção e gestão em todas as instâncias do SUS. Brasília, 2004. 20p. (Série B. Textos Básicos de Saúde).

BRASIL. Ministério da Saúde. HumanizaSUS: documento-base para gestores e trabalhadores do SUS. 4. ed. Brasília, 2008.

BRASIL. Ministério da Saúde. HumanizaSUS: trabalho e redes de saúde. Brasília, 2010. (Série B. Textos Básicos de Saúde).

BRASIL. Ministério da Saúde. HumanizaSUS: Política Nacional de Humanização - PNH. Brasília, 2013.

CAMPOS, Gastão W. S. Um método para análise e cogestão de coletivos. São Paulo: Hucitec, 2000.

CAMPOS, Gastão W. S.; CUNHA, Gustavo T.; FIGUEIREDO, Mariana D. Práxis e formação paideia: apoio e cogestão em saúde. São Paulo: Hucitec, 2013.

CECCIM, Ricardo B. Educação Permanente em Saúde: desafio ambicioso e necessário. Interface: Comunicação, Saúde, Educação, Botucatu, v. 9, n. 16, p. 161-177, 2005.

CONCEIÇÃO, Tainá S. A Política Nacional de Humanização e suas implicações para a mudança do modelo de atenção e gestão na saúde: notas preliminares. SER Social, Brasília, v. 11, n. 25, p. 194-220, jul.-dez. 2009.

FERREIRA, Petrucia B. Sentidos atribuidos ao acolhimento nas narrativas das mulheres atendidas em uma maternidade apoiada pela Rede Cegonha. 2014. 76 f. Dissertação (Mestrado em Ciências) - Instituto Fernandes Figueira, Fundação Oswaldo Cruz, Rio de Janeiro, 2015.

MARTINS, Catia P. A Politica Nacional de Humanização na produção de inflexões no modelo hegemônico de cuidar e gerir no SUS: habitar um paradoxo. 2015. 192f. Tese (Doutorado em Psicologia) - Universidade Estadual Paulista, Assis, São Paulo, 2015.

MINAYO, Maria C. S. O desafio do conhecimento: pesquisa qualitativa em saúde. 14. ed. São Paulo: Hucitec, 2014

MORI, Maria E.; OLIVEIRA, Olga V. M. Os coletivos da Política Nacional de Humanização (PNH): a cogestão em ato. Interface: Comunicação, Saúde, Educação, Botucatu, v. 13, supl. 1, p. 627-640, 2009.

OLIVEIRA, Gustavo N. Devir apoiador: uma cartografia da função apoio. 2011. 175f. Tese (Doutorado em Saúde Coletiva)-Universidade Estadual de Campinas, Campinas, 2011.

OLIVEIRA, Gustavo N. O apoio institucional aos processos de democratização das relações de trabalho na perspectiva da humanização. Tempus: Actas de Saúde Coletiva, Brasília, v. 6, n.2, p. 223-235, 2012.

PASCHE, Dário F. Política Nacional de Humanização como aposta na produção coletiva de mudanças nos modos de gerir e cuidar. Interface: Comunicação, Saúde, Educação, Botucatu, v. 13, supl. 1, p. 701-708, 2009.

PASCHE, Dário F.; PASSOS, Eduardo; HENNINGTON, Élida A. Cinco anos da Política Nacional de Humanização: trajetória de uma política pública. Ciência \& Saúde Coletiva, Rio de Janeiro, v. 16, n. 11, p. 4.541-4.548, 2011.

PEREIRA-JUNIOR, Nilton; CAMPOS, Gastão W. S. O apoio institucional no Sistema Único de Saúde (SUS): os dilemas da integração interfe- 
derativa e da cogestão. Interface: Comunicação, Saúde, Educação, Botucatu, v. 18, supl. 1, p. 895-908, 2014.

PINHEIRO, Roseni et al. (orgs.). Apoiando a gestão do SUS em Rio Branco, Acre: a estratégia da incubadora de integralidade no desenvolvimento institucional local. 1. ed. v. 1. Rio de Janeiro: Cepesc, IMS/UERJ, Abrasco, 2013. 340 p.

PUCCINI, Paulo T.; CECÍLIO, Luiz C. O. A humanização dos serviços e o direito à saúde. Cadernos de Saúde Pública, Rio de Janeiro, v. 20, n. 5, p. 1.342-1.353, 2004.

SANTOS-FILHO, Serafim B.; BARROS, Maria E. B. (orgs.). Trabalhador da saúde: muito prazer! - protagonismo dos trabalhadores na gestão do trabalho em saúde. Ijuí: Unijuí, 2007.
SILVA, Fabio H.; BARROS, Maria E. B.; MARTINS, Cátia P. Experimentações e reflexões sobre o apoio institucional em saúde: trabalho a partir do HumanizaSUS. Interface: Comunicação, Saúde, Educação, Botucatu, v. 16, n. 55, p. 1.157-1.168, 2015.

VASCONCELOS, Michele F. F.; MORSCHEL, Aline. O apoio institucional e a produção de redes: do desassossego dos mapas vigentes na Saúde Coletiva. Interface: Comunicação, Saúde, Educação, Botucatu, v. 13, supl. 1, p. 729-738, 2009.

Recebido em 17/01/2017.

Aprovado em 30/06/2017. 